Harry Far

\title{
Dynamic behaviour of unbraced steel frames resting on soft ground
}

\begin{abstract}
Many recent earthquakes clearly illustrate the importance of local ground properties for the dynamic response of structures. The dynamic response of an engineering structure is influenced by the medium on which it is founded. On solid rock, a fixed-base structural response occurs which can be evaluated by subjecting the foundation to the freefield ground motion occurring in the absence of the structure. However, on deformable ground, a feedback loop exists. In other words, when a feedback loop exists, the structure responds to the dynamics of the soil, while the soil also responds to the dynamics of the structure. Structural response is then governed by the interplay between the characteristics of the ground, the structure and the input motion. This study involved a numerical investigation of the dynamic behaviour of unbraced steel frames resting on soft ground. Two types of mid-rise unbraced steel frame, including 5- and 15-storey buildings on a soft soil deposit, were selected and analysed under the influence of three different earthquake acceleration records. The above-mentioned frames were analysed under two different boundary conditions: i) fixed-base (no soil-structure interaction) and ii) flexible-base (considering soil-structure interaction). The results of the analyses in terms of structural forces and lateral displacements for the above-mentioned boundary conditions are compared and discussed.
\end{abstract}

\section{Introduction}

The Mexico City earthquake in 1985 and Christchurch (New Zealand) earthquake in 2011 clearly illustrate the importance of local soil properties for the earthquake response of structures. These earthquakes demonstrated that the rock motions could be significantly amplified at the base of the structure. Therefore, there is a strong engineering motivation for a site-dependent dynamic response analysis for many foundations in order to determine the free-field earthquake motions. Recent studies [1-4] have revealed that the performance level of steel unbraced frames is very sensitive to lateral deformations and drifts. Performance levels describe the states of structures after being subjected to a certain hazard level and are classified as: fully operational, operational, life safe, near collapse, or collapse [5]. Overall lateral deflection, ductility demand and inter-storey drifts are the most commonly used damage parameters. The above-mentioned five qualitative performance levels are related to the corresponding quantitative maximum inter-storey drifts (as a damage parameter): $<0 \cdot 2 \%,<0 \cdot 5 \%,<$ $1 \cdot 5 \%,<2 \cdot 5 \%$ and $>2 \cdot 5 \%$ respectively.

Several studies [6-8] have reported that soil-structure interaction can increase the lateral deflections and corresponding inter-storey drifts of the structure, forcing it to behave in the inelastic range and leading to severe damage to the structure. Ground motions that are not affected by the presence of structures are referred to as free-field motions. When a structure resting on solid rock is subjected to the seismic loads of an earthquake, the high stiffness of the rock compels the rock motion to be very close to the free-field motion. Structures founded on rock are assumed to be fixed-base structures. However, the same structure would respond differently if supported on a soft soil deposit. The inability of the foundation to conform to the deformations of the free-field motion would cause the motion of the base of the structure to deviate from the free-field motion. The dynamic response of the structure itself would induce deformation in the supporting soil. This process, in which the response of the soil influences the motion of the structure and the response of the structure influences the motion of the soil, is referred to as soil-structure interaction (SSI).

The soil medium beneath the structure influences the seismic behaviour and response of the structure when an earthquake occurs. If the supporting soil is stiff enough, the response of the structure will not be much affected by the support condition. Therefore, the structure can be assumed to be fixed-base. If 
the foundation soil is flexible, it affects the overall structural response and, consequently, the soilstructure interaction effects are considerable.

\section{Method of dynamic analysis of soil-structure system}

In recent years, several attempts have been made to develop analytical methods for assessing the response of structures and supporting soil media under seismic loading conditions. Successful application of these methods for determining ground seismic response is vitally dependent on the incorporation of the soil properties in the analyses. As a result, substantial effort has expended on the determination of soil attributes for use in these analytical procedures. There are two main analytical procedures for the dynamic analysis of soil-structure systems under seismic loads, namely, equivalentlinear and fully non-linear methods.

Byrne et al. [9] provided some overviews of the above-mentioned methods and discuss the benefit of the non-linear numerical method over the equivalent-linear method for different practical applications. The equivalent-linear method is not appropriate for use in dynamic soil-structure interaction analyses because it does not capture directly any non-linear effects and assumes linearity during the solution process. In addition, strain-dependent modulus and damping functions are only taken into account in an average sense in order to approximate some effects of non-linearity (e.g. damping and material softening). They concluded that the most appropriate method for the dynamic analysis of a soil-structure system is the fully non-linear method. This method correctly represents the physics and follows the realistic stress-strain relation. Considering the above-mentioned priorities of the fully non-linear method for the dynamic analysis of soil-structure systems, this method was used in this research in order to obtain reliable results.

\section{Geotechnical and structural characteristics of models}

\subsection{Characteristics of structural models}

This research looked at two structural models, consisting of 5- and 15-storey models, representing the conventional types of building in a relatively high-risk earthquake-prone zone, as per specifications mentioned in Table 1. In the selection of the frame spans, an attempt was made to make this width conform to the architectural norms and construction practices of the conventional buildings in megacities.

Table 1. Dimensional characteristics of frames studied

\begin{tabular}{|l|l|l|l|l|l|l|}
\hline $\begin{array}{l}\text { Reference } \\
\text { name } \\
\text { (code) }\end{array}$ & $\begin{array}{l}\text { Number } \\
\text { of } \\
\text { storeys }\end{array}$ & $\begin{array}{l}\text { Number } \\
\text { of } \\
\text { bays }\end{array}$ & $\begin{array}{l}\text { Storey } \\
\text { height } \\
(\mathrm{m})\end{array}$ & $\begin{array}{l}\text { Storey } \\
\text { width } \\
(\mathrm{m})\end{array}$ & $\begin{array}{l}\text { Total } \\
\text { height } \\
(\mathrm{m})\end{array}$ & $\begin{array}{l}\text { Total } \\
\text { width } \\
(\mathrm{m})\end{array}$ \\
\hline S5 & 5 & 3 & 3 & 4 & 15 & 12 \\
S15 & 15 & 3 & 3 & 4 & 45 & 12 \\
\hline
\end{tabular}

The above-mentioned frames, as fixed-base structures, were modelled and loaded vertically (dead and live loads) and laterally (seismic loads) according to the Australian Standards AS1170. Dynamic analyses of the structures for the design were carried out using the dynamic spectral (modal) analysis method according to the normalized response spectra of AS1170.4-2007 [10] (Fig. 1) for subsoil class $E_{\mathrm{e}}$ (Vs $\leq$ $150 \mathrm{~m} / \mathrm{s})$. A structural ductility factor $\mu=4$ was used, also performance factor $S_{p}=0.67$ for fully ductile steel moment-resisting frames and hazard factor $Z=0.22$ for a relatively high-risk zone. Structural sections were then designed according to AS4100-1998 (Steel Structures) [11] following the seismic analyses.

\subsection{Geotechnical characteristics of subsoil model}

One type of soft clayey soil representing type $E_{e}$ according to the classification of AS1170.4-2007 (Earthquake Actions in Australia) was selected in this research. Since Galal and Naimi [12] showed that for moment-resisting building frames up to 20 storeys, considering the effect of SSI on seismic behaviour is only necessary for structures resting on soft soil deposits with a shear wave velocity $<180$ $\mathrm{m} / \mathrm{s}$, only subsoil class $E_{e}$ fell into this category and was the only class examined in this research. The characteristics of the soil employed are summarized in Table 2, and have been extracted from the actual 
geotechnical report. Therefore, these parameters have merit over the assumed parameters, which may not completely conform to the reality.

Table 2. Geotechnical characteristics of soft soil utilized

\begin{tabular}{|c|c|c|c|c|c|c|c|}
\hline $\begin{array}{c}\text { Soil type } \\
(\mathrm{AS} 1170)\end{array}$ & $\begin{array}{c}\text { Shear } \\
\text { wave } \\
\text { velocity } \\
V s(\mathrm{~m} / \mathrm{s})\end{array}$ & $\begin{array}{c}\text { Unified } \\
\text { classification }\end{array}$ & $\begin{array}{c}\text { Shear } \\
\text { modulus } \\
G \max (\mathrm{KPa})\end{array}$ & $\begin{array}{c}\rho \\
\left(\mathrm{Kg} / \mathrm{m}^{3}\right)\end{array}$ & $\begin{array}{c}\text { Poisson's } \\
\text { ratio }\end{array}$ & SPT & $\begin{array}{c}\text { Plastic } \\
\text { index } \\
(P I)\end{array}$ \\
\hline $\mathrm{E}_{\mathrm{e}}$ & 150 & $\mathrm{CL}$ & 33100 & 1471 & 0.40 & 6 & 15 \\
\hline
\end{tabular}

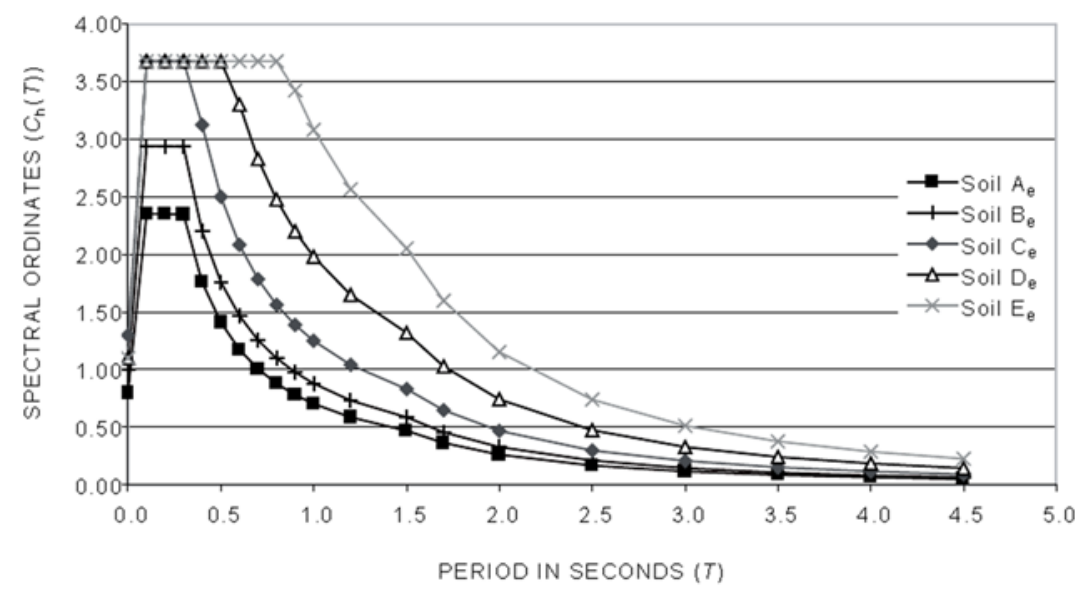

Fig. 1. Normalized response spectra for different subsoil classes [10]

The shear wave velocity value shown in Table 2 was obtained from a down-hole test, which is a lowstrain in situ method. This test generates a cyclic shear strain of about $10^{-4}$ percent, where the resulting shear modulus is called $G_{\max }$. In the event of an earthquake, the cyclic shear strain amplitude increases and the shear strain modulus and damping ratio - which both vary with the cyclic shear strain amplitude - change relatively. The damping and tangent modulus are selected to be appropriate to the level of excitation at each point in time and space, which is called the hysteretic damping algorithm.

The fully non-linear time history dynamic analysis employed in this study adopted the hysteretic damping algorithm, which captures the hysteresis curves and energy-absorbing characteristics of the real soil. A small strain shear modulus and damping degradation of the soil with the strain level can be considered in the modelling precisely. In the soil-structure model, the built-in tangent modulus function presented by [13], known as the Hardin model, is employed, as this model provides a reliable fit to backbone curves presented by [14] for clay in order to implement hysteretic damping in the model (Fig. 2). The model adopted in FLAC2D generates backbone curves for clay, adopting $\gamma_{\text {ref }}=0.06$ as a numerical fitting parameter.

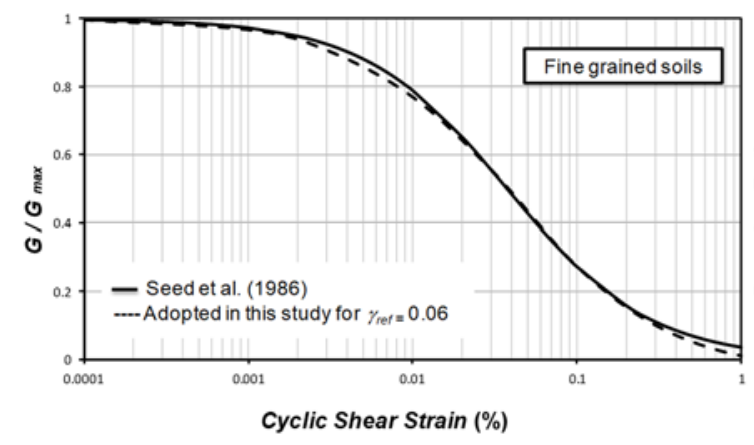

a)

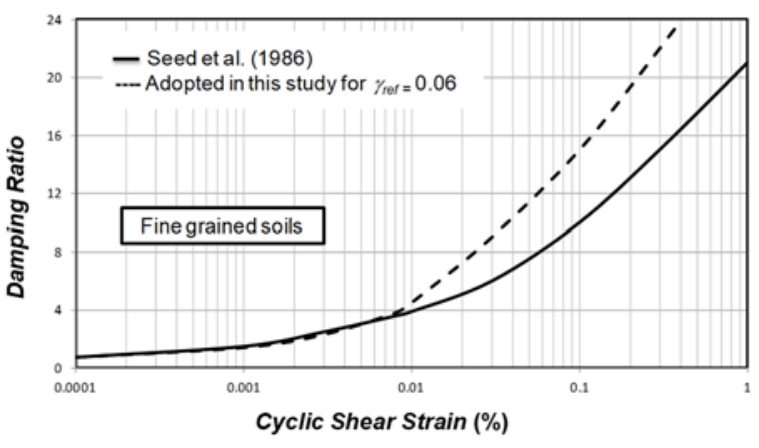

b) 
Fig. 2. Fitting curves for clay adopted in this study: a) relation between $G / G_{\max }$ and shear strain, b) relation between material damping ratio and shear strain

Using the fully non-linear method for a dynamic analysis enables us to apply these charts directly to the model and incorporate the soil non-linearity precisely.

The normal and shear spring stiffness values for the soil utilized have been determined to be equal to $2.0 \times 10^{6} \mathrm{kPa} / \mathrm{m}$.

\section{Numerical simulation of soil-structure system}

The equations governing the motion of the structure incorporating foundation interaction and the method of solving these equations are relatively complex. Therefore, the direct method using finite difference software, FLAC2D, was employed in this study to model the soil-structure system and solve the equations for the complex geometries. FLAC (Fast Lagrangian Analysis of Continua) is a two-dimensional explicit finite difference program for engineering mechanics computations. This program simulates the behaviour of structures built of soil, rock, steel, concrete or other materials. Materials are represented by elements that can be adjusted to fit the geometry of the model. Each element behaves according to a prescribed linear or nonlinear stress-strain law in response to the applied forces or boundary restraints. The program offers a wide range of capabilities for solving complex problems in mechanics [15].

The soil-structure model (Fig. 3.) comprises beam elements to model structural elements, twodimensional plane strain grid elements to model soil medium, fixed boundaries to model the bedrock, quiet boundaries (viscous boundaries) to avoid reflective waves produced by soil lateral boundaries and interface elements to simulate frictional contact and probable slip due to the seismic excitation.

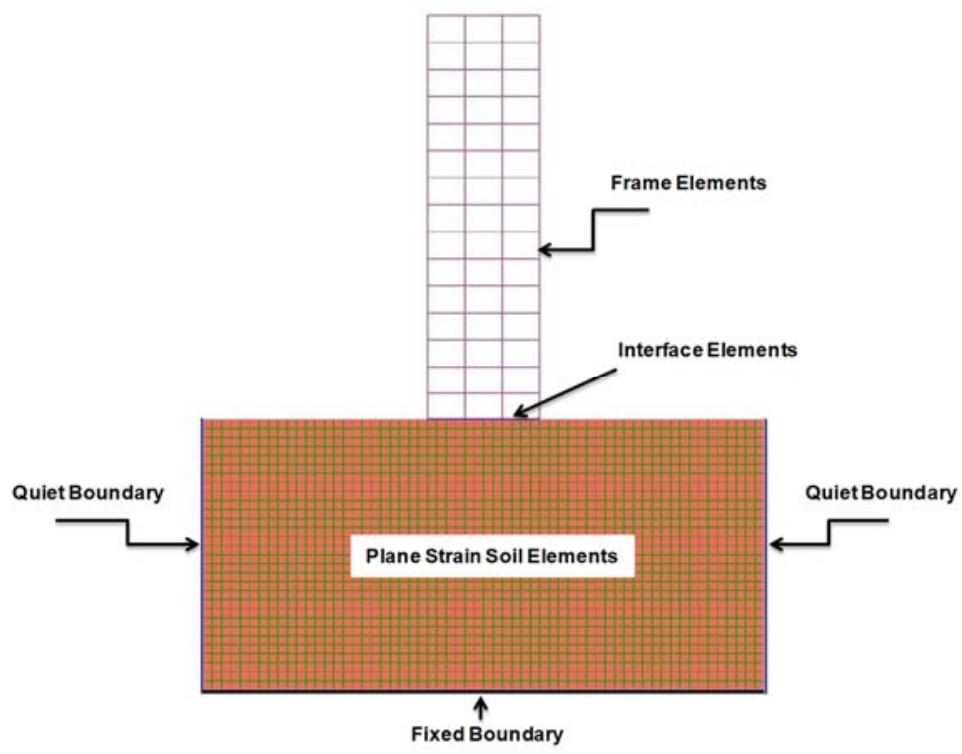

Fig. 3. Components of the soil-structure model in FLAC 2D

According to Rayhani and Naggar [16], the horizontal distance between soil boundaries is assumed to be five times the structure width $(60 \mathrm{~m})$, and the bedrock depth is assumed to be $30 \mathrm{~m}$ in the research results.

\section{Dynamic analysis of soil-structure interaction}

In this study, a fully non-linear time history dynamic analysis has been exploited using FLAC 2D to define the seismic response of steel moment-resisting frames under the influence of SSI. Dynamic analyses were carried out for two different systems: i) fixed-base columns on rigid ground (Fig. 4) and ii) frames with subsoil (Fig. 5.) using the direct method of soil-structure interaction analysis called flexible-base. 


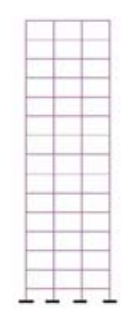

Fig. 4. Fixed-base model

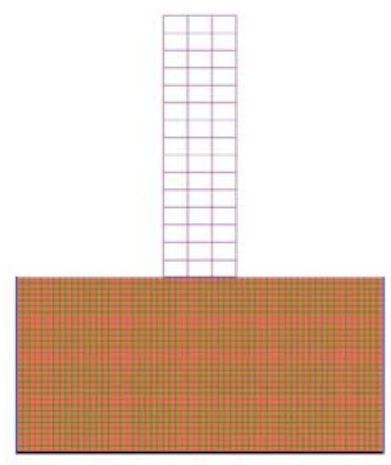

Fig. 5. Flexible-base model

Earthquake ground motions were applied to both systems in two different ways. In the case of modelling soil and structures simultaneously using the direct method (flexible-base), the earthquake records were applied to the combination of soil and structure directly at bedrock level, whereas in the case of modelling the structure as fixed-base (without soil), the earthquake records were applied to the base of the structural model.

In order to perform a comprehensive investigation of the seismic response of structure models, two nearfield earthquake acceleration records (Kobe, 1995, and Northridge, 1994) and one far-field earthquake acceleration record (Hachinohe, 1968) were selected and utilized in a time history analysis (Table 3). These earthquakes have been chosen by the International Association for Structural Control and Monitoring for benchmark seismic studies [17].

Table 3. Earthquake ground motions used in analyses

\begin{tabular}{|c|c|c|c|c|c|c|c|}
\hline Earthquake & Country & Year & $\begin{array}{c}\text { PGA } \\
(\mathrm{g})\end{array}$ & $\begin{array}{c}\text { Mw } \\
(\mathrm{R})\end{array}$ & $\begin{array}{c}\mathrm{T}(\mathrm{S}) \\
\text { Duration }\end{array}$ & Type & $\begin{array}{c}\text { Hypocentral } \\
\text { distance } \\
(\mathrm{km})\end{array}$ \\
\hline Northridge & USA & 1994 & 0.843 & 6.7 & 30.0 & near-field & 9.2 \\
Kobe & Japan & 1995 & 0.833 & 6.8 & 56.0 & near-field & 7.4 \\
Hachinohe & Japan & 1968 & 0.229 & 7.5 & 36.0 & far-field & 14.1 \\
\hline
\end{tabular}

\section{Results and discussion}

The results of both cases, including base shear and inter-storey drifts, have been determined and compared. According to the results summarized in Table 4, the ratio of the base shear of the flexiblebase models $(\tilde{V})$ to that of fixed-base models $(V)$ is $<1$ in all models. Therefore, the base shear of structures modelled with soil as flexible-base is always less than the base shear of structures modelled as fixed-base. These results show good agreement with the NEHRP-1997 [18] regulations.

Table 4. Ratio of base shear of flexible-base to fixed-base models

\begin{tabular}{|l|l|l|l|l|}
\hline $\begin{array}{l}\text { Reference } \\
\text { name }\end{array}$ & Earthquake & $V(\mathrm{KN})$ & $\tilde{V}(\mathrm{KN})$ & $\frac{\tilde{V}}{V}$ \\
\hline \multirow{3}{*}{ S5 } & Northridge & 220 & 111 & 0.50 \\
\cline { 2 - 5 } & Kobe & 240 & 118 & 0.49 \\
\cline { 2 - 5 } & Hachinohe & 80 & 42 & 0.52 \\
\hline \multirow{3}{*}{ S15 } & Northridge & 997 & 140 & 0.14 \\
\cline { 2 - 5 } & Kobe & 1400 & 230 & 0.16 \\
\cline { 2 - 5 } & Hachinohe & 300 & 80 & 0.26 \\
\hline
\end{tabular}

By comparing the inter-storey drifts, it can be seen that the lateral drifts of the flexible-base model substantially increase in comparison to the fixed-base model (Figs 6, 7 and 8). Generally, these lateral drift increments are more critical and noticeable for 15-storey models than for 5-storey models. 


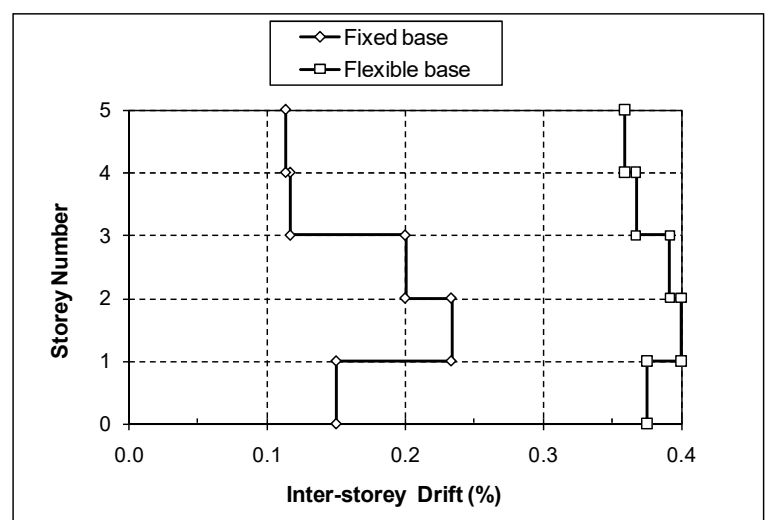

a)

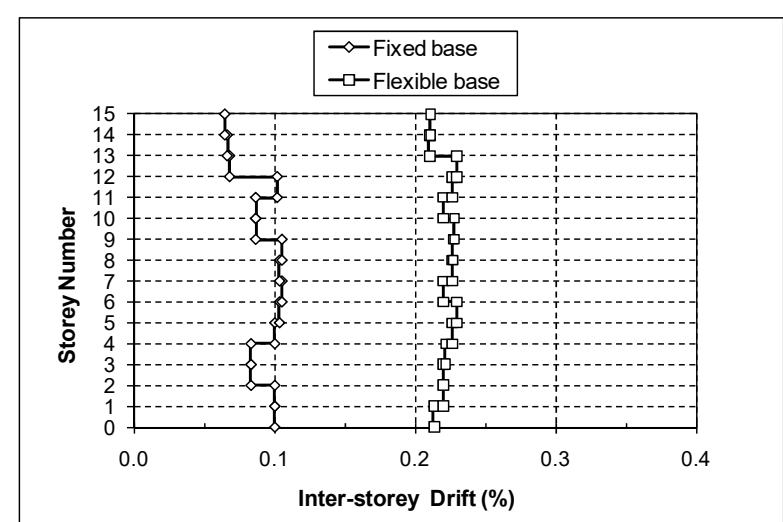

b)

Fig. 6. Inter-storey drifts comparison for two cases of flexible-base and fixed-base under the influence of the Northridge earthquake: a) model S5, b) model S15

Taking SSI effects into account, the spectral displacement $S_{d}$ may change considerably with the change in natural period. Therefore, such an increase in the natural period may considerably alter the response of the building frames under seismic excitation.

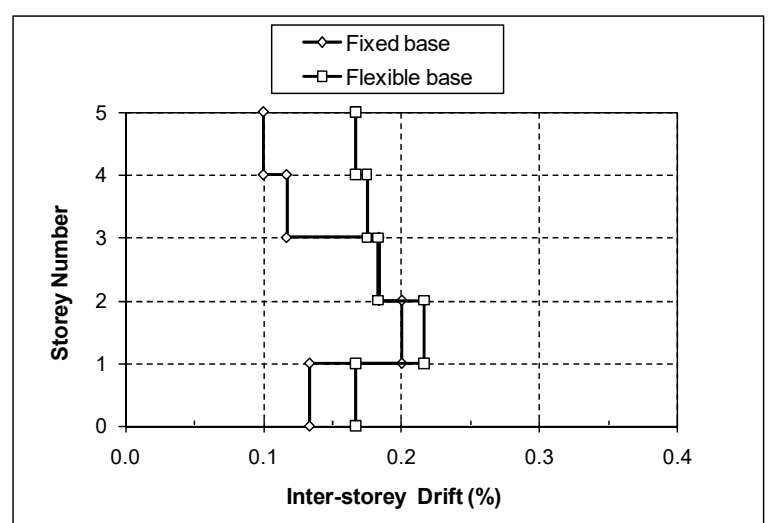

a)

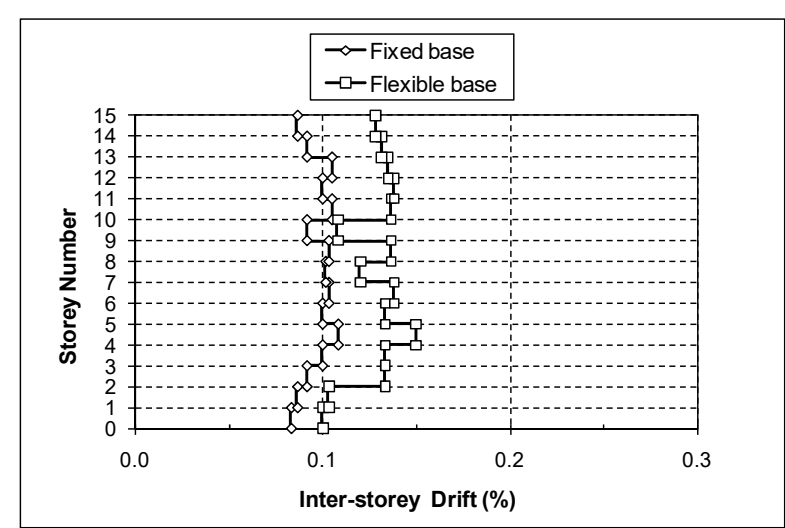

b)

Fig. 7. Inter-storey drifts comparison for two cases of flexible-base and fixed-base under the influence of the Kobe earthquake: a) model S5, b) model S15

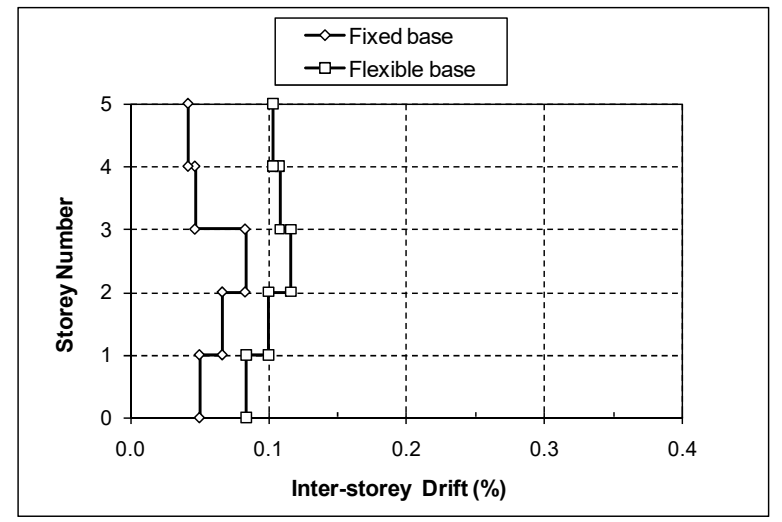

a)

Fig. 8. Inter-storey drifts comparison for two cases of flexib)

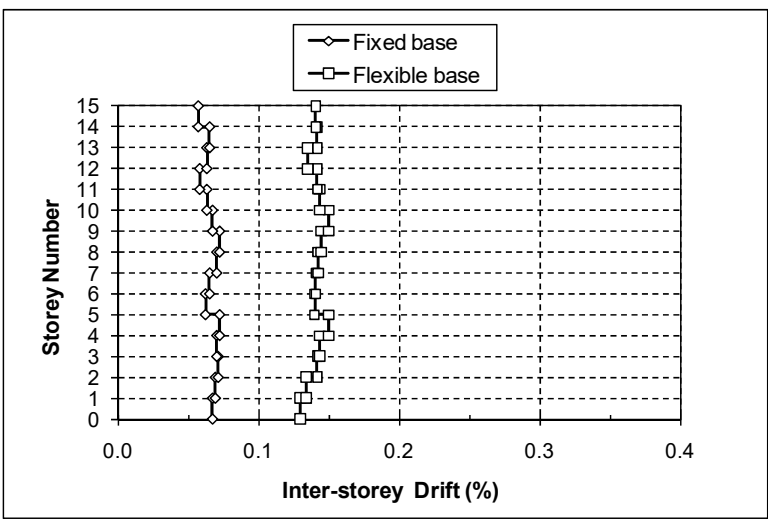
Hachinohe earthquake: a) model S5, b) model S15

In the case of the steel moment-resisting building frames resting on soft soil deposits utilized here, the natural period lies in the long-period region of the response spectrum curve due to the natural period lengthening for such systems. Hence, the displacement response tends to increase. Therefore, the performance level of the structure may be changed from life safe into near collapse or total collapse. 


\section{Conclusions}

According to the results of the numerical investigation conducted in this study regarding two 5- and 15storey steel moment-resisting building frames resting on soft clayey soil, it was observed that the base shear of the structures modelled with soil as flexible-base is always less than the base shear of the structures modelled as fixed-base, whereas the inter-storey drifts of the structures resting on soft soil deposits substantially increase (more than twice) when soil-structure interaction is considered. The amplification of the lateral deflections and corresponding inter-storey drifts of flexible-base models resting on soil class $E_{e}$ can change the performance level of the structures from life safe to near collapse or total collapse, which is extremely dangerous and a threat to safety. As a result, soil-structure interaction has significant effects on the seismic response of regular mid-rise steel moment-resisting building frames resting on soft soils. Therefore, it is essential to consider SSI effects in the seismic design of steel unbraced building frames resting on soft ground. It can be concluded that the conventional design procedures excluding SSI may not be adequate to guarantee the structural safety of regular mid-rise moment-resisting building frames resting on soft soil deposits.

\section{References}

[1] Tabatabiefar, H. R.; Mansoury, B.: Detail Design, Building and Commissioning of Tall Building Structural Models for Experimental Shaking Table Tests. The Structural Design of Tall and Special Buildings 25 (2016), No. 8, pp. 357-374.

[2] Far, H.; Saleh, A.; Firouzianhaji, A.: A Simplified Method to Determine Shear Stiffness of Thin Walled Cold Formed Steel Storage Rack Frames. Journal of Constructional Steel Research 138 (2017), pp.799-805.

[3] Haydar, H.; Far, H.; Saleh, A.: Portal Steel Trusses vs Portal Steel Frames for Long Span Industrial Buildings. Steel Construction 11 (2018), No. 2.

[4] Ingkiriwang, Y. G.; Far, H.: Numerical Investigation on Design of Single-Span Steel Portal Frames Using Effective Length Method and Direct Analysis Method. Steel Construction 11 (2018), No. 2.

[5] FEMA 440: NEHRP Recommended Provisions for Improvement of Nonlinear Static Seismic Analysis Procedures. ATC-55 Project, Emergency Management Agency, Washington, D.C., 2005.

[6] Fatahi, B.; Tabatabiefar, H. R.; Samali, B.: Performance Based Assessment of Dynamic Soil-Structure Interaction Effects on Seismic Response of Building Frame, Proceedings of Georisk 2011 - Geotechnical Risk Assessment \& Management (Geotechnical Special Publ. No. 224), American Society of Civil Engineers (ASCE), 2011, pp. 344-351.

[7] Fatahi, B.; Tabatabaiefar, H. R.; Samali, B.: Soil-Structure Interaction vs Site Effect for Seismic Design of Tall Buildings on Soft Soil. Geomechanics and Engineering 6 (2014), No. 3, pp. 293-320.

[8] Tabatabiefar, H. R.; Fatahi, B.; Ghabraie, K.; Zhou, W.: Evaluation of Numerical Procedures to Determine Seismic Response of Structures under Influence of Soil-Structure Interaction. Structural Engineering and Mechanics 56 (2015), No. 1, pp. 27-47.

[9] Byrne, P. M.; Wijewickreme, D.: Liquefaction Resistance and Post-Liquefaction Response of Soils for Seismic Design of Buildings in Greater Vancouver. 59th Canadian Geotechnical Conference, 2006, pp. 1267-1278.

[10] AS1170: Structural Design Actions, Standards Australia, NSW, Australia, 2007.

[11] AS4100: Steel Structures, Standards Australia, NSW, Australia, 1998.

[12] Galal, K.; Naimi, M.: Effect of conditions on the Response of Reinforced Concrete Tall Structures to Near Fault Earthquakes. The Structural Design of Tall and Special Buildings 17 (2008), No. 3, pp. 541-562.

[13] Hardin, B. O.; Drnevich, V. P.: Shear Modulus and Damping in Soils: Design Equations and Curves. Journal of Soil Mechanics and Foundation 7 (1972), No. 8, pp. 667-692.

[14] Veletsos, A. S.; Meek, J. W.: Dynamic Behaviour of Building-Foundation system. Journal of Earthquake Engineering and Structural Dynamics 3 (1974), No. 2, pp 121-138.

[15] Itasca Consulting Group: FLAC2D: Fast Lagrangian Analysis of Continua, version 6.0, User's manual, Minneapolis, 2008. 
[16] Rayhani, M. H.; El Naggar, M. H.: Numerical Modelling of Seismic Response of Rigid Foundation on Soft Soil. International Journal of Geomechanics 8 (2008), No. 6, pp. 336-346.

[17] Karamodin, A. K.; Kazemi, H. H.: Semi-active Control of Structures Using Neuro-Predictive Algorithm for MR Dampers. Structural Control and Health Monitoring 17 (2008), No. 3, pp. 237-253.

[18] NEHRP: Recommended Provisions for Seismic Regulation for New Buildings and Other Structures - Part 2 : Commentary FEMA 303, Federal Emergency Management Agency, Washington, DC, USA, 1997.

Keywords: unbraced steel frames; structural response; deformable ground; dynamic behaviour

\section{Author}

\section{Harry Far}

Centre for Built Infrastructure Research (CBIR)

School of Civil \& Environmental Engineering

University of Technology Sydney (UTS)

Sydney

Australia

Email:Harry.Far@uts.edu.au 